\title{
Added Value and Constraints of Transdisciplinary Case Studies in Environmental Science Curricula
}

\author{
Margien C. Bootsma, * Walter J.V. Vermeulen, Jerry van Dijk and Paul P. Schot \\ Copernicus Institute of Sustainable Development, Utrecht University, the Netherlands
}

\begin{abstract}
Sustainable development issues are characterised by their multidisciplinary character, and the fact they are not merely an academic exercise but pertain to real-world problems. Academic sustainable development curricula should therefore not only focus on developing the analytical and research skills and theoretical and professional knowledge of their students; they should also include real-world learning opportunities in the curriculum. This paper evaluates the added value and constraints associated with a specific type of real-world learning called transdisciplinary learning, based on the experiences with three courses from the undergraduate and graduate Environmental Sciences curriculum of Utrecht University, the Netherlands. In these courses, students carry out a small multidisciplinary research project or a consultancy project for a real-life client. It is concluded that transdisciplinary courses have clear added value for students, involved stakeholders, and the university alike, making them an essential part of the sustainable development curricula. The main constraint is the balance between academic quality (grading) vs stakeholder satisfaction. Although time investments for adequate problem definition with clients may constitute a constraint for university supervisors, it has the potential added value of sparking research cooperation with societal stakeholders, and internships and employment opportunities for graduates. Copyright (C) 2013 John Wiley \& Sons, Ltd and ERP Environment.
\end{abstract}

Received 6 December 2011; revised 26 March 2012; accepted 27 August 2012

Keywords: sustainable development; curricula; real-world learning; higher education; students; societal stakeholders; university

\section{Introduction}

USTAINABLE DEVELOPMENT IS CHARACTERISED BY ITS MULTIDISCIPLINARY CHARACTER, SINCE SUSTAINABLE DEVELOPMENT issues show large complexity as a result of mutual interactions between social, economic, and biophysical systems. Therefore, education for sustainable development should not be an academic exercise but rather be addressing real-world problems. Traditional scientific approaches tend to focus on different disciplinary aspects of a problem in isolation, using an 'objective' analytical perspective. In contrast, it has been argued that sustainable development issues are in need of a 'Mode 2' or 'Post-Normal Science' approach, in which there are multiple legitimate perspectives, related to values and world views of individuals or groups (Van Egmond and De Vries, 20II), while the full complexity, including its uncertainty, should be part of the scientific analysis

*Correspondence to: Margien C. Bootsma, Utrecht University, Copernicus Institute of Sustainable Development, Department of Innovation, Environmental and Energy Sciences, P.O. Box 80115, NL - 3508 TC Utrecht, the Netherlands. E-mail: m.c.bootsma@uu.nl 
(Funtowitz and Ravetz, I993; Hessels and Van Lente, 2008). Sustainability science seeks to combine the production of knowledge in academia and the requests for knowledge to solve complex problems with transdisciplinary research activities (Scholz et al., 2000, 2006; Tress et al., 2005; Godemann, 2008; Pohl, 2008). Acknowledging the diversity of definitions of the terms multidisciplinary, interdisciplinary, and transdisciplinary (Mitchell, 2005; Tress et al., 2005; Godemann, 2008; Pohl, 2008; Schmidt, 2008; Jones et al., 20I0), we define transdisciplinary studies as studies that both integrate academic researchers from different disciplines, and integrate academics with non-academic participants such as land managers, policymakers, and the public, to create new knowledge and research a common goal (Tress et al., 2005).

Academic environmental science and sustainable development programmes aim to develop students' competencies for working on these complex real-world problems. Therefore, programmes should not only focus on developing the analytical and research skills and theoretical and professional knowledge of their students, but should also include exercises aimed at developing complex problem-solving skills as well as the ability to collaborate successfully with experts and stakeholders (Runhaar et al., 2005; 2006; Barth et al., 2007; Vincent and Focht, 2009; Bootsma and Vermeulen, 20II; Altomonte et al., 20I2). This can be realised by including real-world case studies and projects in the curriculum. Different types of courses and approaches with different goals have been reported, which can roughly be categorised into three types.

First, activities can be aimed at 'bringing the real-world into the classroom' (Brundiers et al., 20Io), e.g. by inviting guest lecturers from industries, governments, or NGOs to present and discuss an actual case from their working practice with the students or by having students analyse and discuss historic or recent cases, for example, the Harvard Case Study Approach (Steiner and Laws, 2006). Moreover, simulation games (e.g. role-playing games or computer games) of real-world cases are potentially effective tools for learning, because they offer a 'collaborative effort of new knowledge, application in action, in a social setting and emotional involvement' (Hofstede et al., 2010; Baumgartner, 2012). These activities enable students to gain insight into the complexity of sustainability problems. Working on case studies and simulation games enables them to practice analysing complex, multidisciplinary problems (with uncertain information), and to develop collaborative skills for group work.

Second, students can go out of the classroom and observe sustainability issues in the field and meet and talk with stakeholders ('visiting the real-world', Brundiers et al., 20I0). In the context of sustainability education, these types of activities can make an important contribution to increase students' understanding of different perspectives on and dimensions of sustainability. Examples are the Farming the Future course of RMIT University, Melbourne (Alvarez and Rogers, 2006) and the STEM approach of Central Connecticut State University (Clark and Button, 20II).

Third, students can be exposed directly to the multifaceted and complex character of real-world problems through internships or transdisciplinary projects ('engaging with the real-world'; Brundiers et al., 2010). The most well-known example in the context of education for sustainable development is the Transdisciplinary Case Study approach developed by ETH Zürich; a hybrid combining learning, research, and application used to learn competencies and skills necessary for research in problems of sustainable development (Scholz et al., 2006; Stauffacher et al., 2006). This approach has inspired a number of programmes in Europe and the USA to introduce comparable courses (Steiner and Posch, 2006; Polk and Knutsson, 2008; Brundiers et al., 20I0). This type of experiential learning is not unique to sustainable development education. In the context of business education, for example, these projects are often referred to as 'student consulting' (Sciglimpaglia and Toole, 2010).

Transdisciplinary case studies can add high value to academic sustainability programmes as well as to the stakeholders involved (Scholz et al., 2006). However, the introduction of such case studies in an academic educational programme is not without potential downsides. Complex real-world sustainability problems, especially when confronted by demanding stakeholders, can be quite challenging and de-motivating to students (Holden et al., 2008). Additionally, stakeholders may not be open to the advice of students (Kearins and Fryer, 20II) and may also be reluctant to share corporate information necessary for the case study, which may seriously hamper both the student's motivation and progress. Similarly, stakeholders involved run a risk because they may have limited influence on the end-product and may end up with an outcome with limited added value. Before integrating transdisciplinary learning in often time-constrained academic curricula, risks and benefits at the approach should therefore be carefully evaluated. 
The aim of this paper is to identify and evaluate the added value and constraints associated with transdisciplinary learning, based on the experience of three transdisciplinary courses from the undergraduate and graduate environmental sciences curriculum at Utrecht University.

\section{Approach}

First, we provide an overview of all courses with real-world cases in Environmental Sciences, Utrecht University. These courses have been classified according to the three categories distinguished by Brundiers et al. (20IO): (I) bringing the real-world into the classroom, (2) visiting the real-world, (3) engaging with the real-world. For the three courses used as examples of real-world transdisciplinary case studies, the main characteristics are described to provide the reader with a contextual background.

Second, we evaluate to what extent the three courses can be considered as 'good examples' of sustainability research education (Brundiers and Wiek, 20II). Brundiers and Wiek (20II) developed a framework of requirements for an 'ideal' setting for sustainability research and education. According to this framework, sustainability education projects should meet requirements concerning the content of the project, the outcomes, and the process. For reasons of compactness, we aggregated the seven original requirements into these three categories. We will score the three transdisciplinary courses on these criteria concerning the content of the project, the outcomes and the process.

Third, we discuss the main factors determining added value and constraints of these types of courses for students, the university, as well as for the involved stakeholders. The factors are based on analyses of course evaluations and alumni research (students) and formal and informal evaluations of courses with stakeholders and university lecturers (stakeholders and university). Finally, we evaluate the added value of transdisciplinary learning experiences to academic sustainable development curricula.

\section{Results}

\section{Courses with Real-World Cases in Environmental Sciences, Utrecht University}

Utrecht University is one of the oldest and the largest universities in the Netherlands. It was founded in ${ }_{15} 6$, and consists of seven faculties with around 7500 staff members. Approximately 30000 students participate in one of 45 undergraduate and ${ }^{6} 67$ graduate programmes. The University has offered courses in Environmental Sciences for over 30 years (since 1978) and degrees in Environmental Studies/Sciences for over 20 years (since I989; Bootsma and Vermeulen, 20II). As a result of the Bologna process in which European countries agreed to work on a more harmonised curriculum structure, since 2002 Utrecht University has offered a Bachelor's programme in Environmental Studies and Environmental Sciences, and a Master's degree in Sustainable Development. This MSc programme consists of an integrated part and four specialisation tracks, of which two tracks have a natural science focus and the other two have a social science focus. The focus of the programme has broadened from environmental science to sustainability science in recent years.

Analysis of the courses offered with respect to their input of real-world cases shows the following results with respect to the three types distinguished by Brundiers et al. (2010).

Type-1 Courses - Bringing the Real-World into the Classroom

In all courses in the curriculum, real-world problems are addressed in the classroom by discussing and analysing real-life cases presented by guest lecturers from industries, governments, and NGOs. In a number of courses, simulation games mimicking real-world cases are included in the programme, such as the Environmental Impact Assessment Game, a role-play game in which an Environmental Impact Assessment procedure is simulated, and Fishbanks, a role-play game developed by Dennis Meadows in which management of common pool of resources 
and the consequences of stakeholders' choices for sustainability of fish populations are simulated. This game allows students to experience the 'tragedy of the commons', and the way human nature leads us to look at the short term, and in so doing, can destroy resources critical for long-term survival. Another example is in the course Evaluation and Design of Environmental Policy, in which students work in a virtual online consultancy firm (Viboa), doing a policy evaluation project, based on real-life examples, but in an artificial online situation with prepared discussions with clients and policymakers.

Type-2 Courses - Visiting the Real-World

Many courses have included one or more excursions or field trips in the programme to organisations and regions related to the theme of the course. Just two examples are an excursion to the Dutch House of Representatives in the context of a course on public administration, and excursions to water boards and field sites in the context of a course on integrated water resources management. During these excursions students see and hear about real-life sustainability issues and interact with stakeholders involved, mainly by information exchange.

Type-3 Courses - Engaging with the Real-World

In the I980s and early I990s, these courses were conducted in a trans-academic setting, in cooperation with the Province of Utrecht. This stakeholder was involved in defining the cases, and in providing necessary data and information through interviews. In the early I990s, this trans-academic approach was abandoned, mainly because of time constraints of the academic staff and of changes in the Provincial organisation. In the following years, the trans-academic setting was simulated by a role-play, in which the professors acted as the stakeholder (i.e. a Water Board). In recent years, a number of projects in which students engage with the real-world have been reintegrated in the curriculum. The first example is in the Environmental Consultancy Project, in which groups of 6-8 undergraduate students from the Environmental Science and Environmental Studies programmes act as a consultancy company to advise a stakeholder on an actual sustainability problem. In the second example, the Sustainable Business Case, small multidisciplinary groups of 3-4 undergraduate students apply the knowledge they have acquired to conduct research in companies and provide these companies with advice on steps towards a more sustainable business performance. In the third example, the Transdisciplinary Sustainability Case Study, graduate students enter the transdisciplinary arena and are confronted with a real-world problem of a real-world client. Students from the 4 master programme specialisation tracks form multidisciplinary groups to analyse the client's multidisciplinary sustainability issue, each from their own specific background. They have to integrate their specialist analysis and advice with that of students with different specialisations, and with the tacit knowledge of stakeholders. The main characteristics of these three courses are summarised in Table I. Finally, students can get extensively engaged in real-world problems by performing part of their MSc thesis research as an internship at a relevant organisation.

\section{Are These Courses Good Examples of Sustainability Research Education?}

Table 2 summarises the extent to which each of the type-3 courses meets the requirements of good examples of sustainability research education as determined by the adapted framework of Brundiers and Wiek (20II).

Content

Requirements

According to Brundiers and Wiek (2OII), if the goal of the learning experience is to engage students in real-world sustainability problems, then the cases addressed should have elements of long-term dynamics, cross-domain and cross-scale complexity, complex cause-effect structure, spatial and temporal specificity, urgency and harmfulness.

Analysis

Our analysis shows that with respect to content, the cases in the Environmental Consultancy Project and the Transdisciplinary Case Study can be considered good examples of actual sustainability problems, because of their relatively complex character, and spatial and temporal specificity. Examples of projects are:

Sustainable water management in the city of Utrecht; The use of biomass for energy production in Utrecht; and Involvement of businesses in the transition into a sustainable urban area. However, stakeholders are reluctant to bring in more 







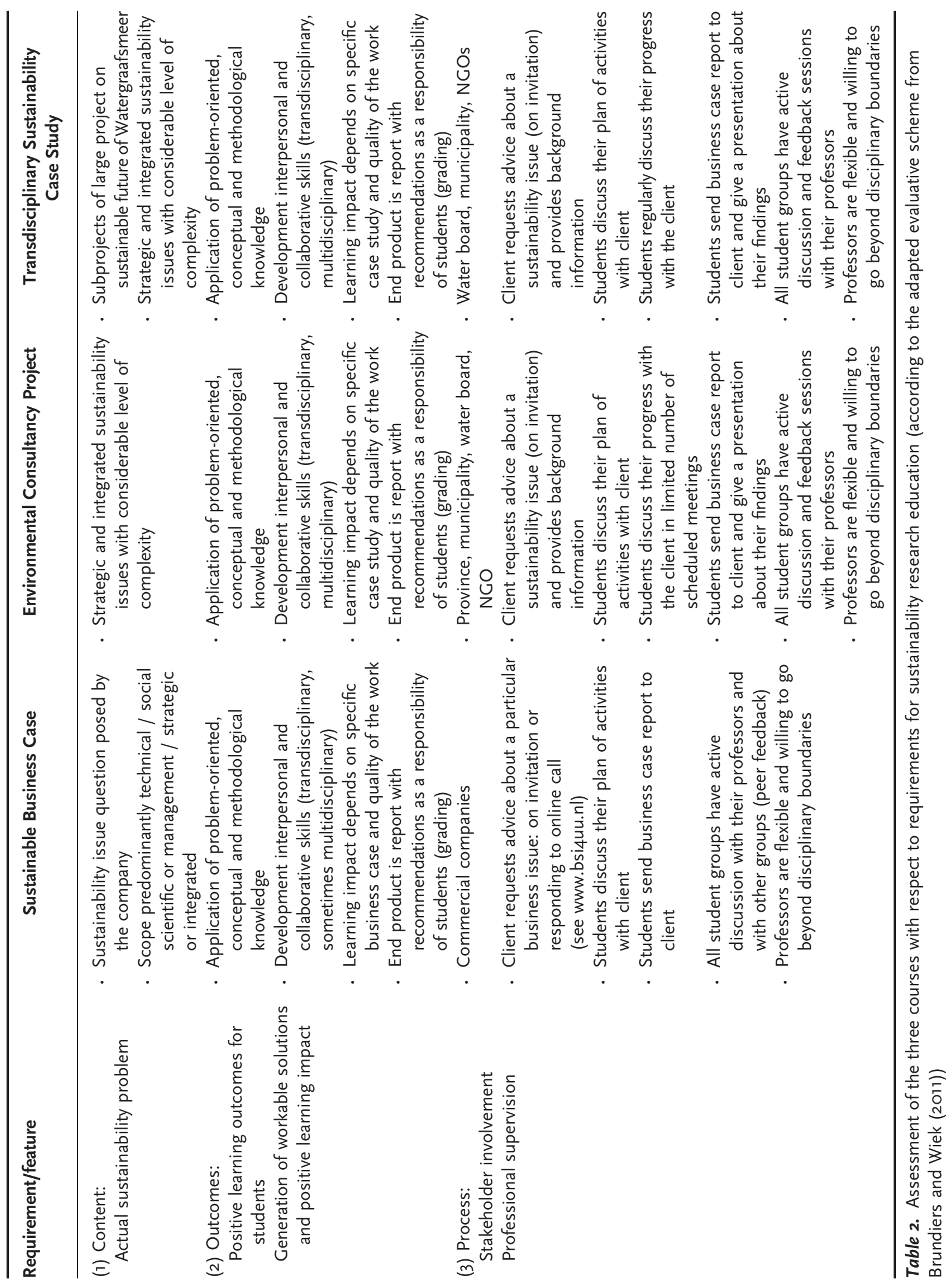


high-stake sustainability problems. Most of the cases brought in by the stakeholders are aimed at testing new ideas or gaining advice about subjects for which no budget is available. The scope of the different cases of the Sustainable Business Case course is generally more practice and solution oriented. The cases vary from predominantly technical questions (e.g. Life Cycle Analysis of using plastic packages for the companies' ink cartridges) to predominantly social scientific or management questions (e.g. Expectations of stakeholders regarding the companies CSR) to questions with an integrated and strategic character (e.g. Companies' strategy to become more sustainable and environmentally friendly).

\section{Outcomes}

Requirements

Transdisciplinary courses have double aims: acquiring a learning outcome for the students involved and developing workable solutions for the practical problem of the societal stakeholder(s). Projects should allow students to develop their competencies in all relevant domains, including problem-oriented and conceptual knowledge, methodological knowledge, the ability to link knowledge to action and interpersonal and collaborative skills. Moreover, the trans-academic setting of the project should enable students to analyse a sustainability problem and develop response and mitigation strategies in collaboration with stakeholders. This helps students recognise they are not only 'subjects of education', but also real-world stakeholders who - through their decisions - contribute to shaping the present and future of society. From the content perspective, projects can be considered successful examples of transdisciplinary cases if they generate workable solutions for the client.

\section{Analysis}

Our analysis reveals that all three courses meet the requirement with respect to outcomes for the students, as they allow students to apply problem-oriented, conceptual and methodological knowledge and to develop their interpersonal and collaborative skills. Despite the possible limitations for direct applicability of the results of students' projects (e.g. exploratory nature of the cases, limited experience of students, the short time span of the course) learning outcomes in terms of a real life consultancy situation can still be evaluated. Next to general academic writing skills (e.g. report structuring, problem description, and writing), delineation of the subject and research questions in collaboration with the stakeholder, writing a customer oriented advice (which is attuned to the stakeholders' wishes, needs and action perspective) are learning outcomes that are specifically evaluated. Furthermore, it is possible to assess specific skills needed for transdisciplinary work. In the Environmental Consultancy Project for instance, an evaluation of personal and group functioning by each of the students is part of the assessment. This evaluation is based on theory about cooperation and multi- and transdisciplinarity. In a limited number of cases, the solutions proposed by the students are being applied in practice. In the case of the Sustainable Business Case afterwards more than two-thirds of the companies have stated that they took next steps in line with the advice students gave them. Sometimes this implies real investments in facilities or activities; in other cases, it implies further elaboration of a suggested alternative.

\section{Process}

\section{Requirements}

Mutual learning of all involved stakeholders is often reported as an important outcome of transdisciplinary research projects (Scholz et al., 2000). The willingness to adopt and implement solutions developed in the project increases when the involved stakeholders request help from the university, when stakeholders and academics take collaborative ownership and when stakeholders are involved in the course project throughout the entire research process (Scholz et al., 2000; Muhar et al., 2006). Faculty involved in the project should be flexible and adaptive and willing to go beyond disciplinary boundaries. In return, lecturers may increase their own sustainability knowledge from their interactions with students and in particular with practitioners from the real-world (Muhar et al., 2006; Holden et al., 2008).

\section{Analysis}

In all three courses, the involved stakeholders are invited to submit a project or case. Thus stakeholders are involved from the start. In the Sustainable Business Case (which only lasts four weeks half-time), students discuss their plan 
with the stakeholder at the start of their project, closely work with the company during the project and report and present the analysis and solutions at the end via a poster presentation in a workshop and on paper in a short report. In the other two courses, the involved stakeholder(s), students and professors discuss progress more frequently during the project, although the feedback of professors and stakeholders is most intensive in the MSc course Transdisciplinary Case Study.

\section{Added Value and Constraints of Transdisciplinary Course Projects}

Table 3 shows the added value and constraints of the three courses from the perspective of the students, stakeholders and university.

\section{Students' Perspective}

Students perceive the contact with real stakeholders as highly motivating and consider these courses as valuable addition to the curriculum. They experience that they are able to translate the knowledge they gained so far into applicable solutions and get a good sense of how stakeholders 'in the field' respond to this knowledge. For them it is also a first encounter with possible future employers. However, they also experience drawbacks to this approach, which in some cases are de-motivating. An important constraint from the students' perspective is the tension between expectations and wishes of the client versus the expectations and grading from the side of the university. Whereas the client prefers a report on workable solutions, the university requires the report to have a sufficient level of scientific analysis. Regarding the development of their interpersonal and collaborative skills, some students do not appreciate group challenges and have difficulty coping with differences in the level of ownership and initiative between group members. Furthermore, these projects have a high working load, which is not always appreciated by students given they are supposed to enroll in two courses during the same period. Finally, in some cases working with Dutch stakeholders causes language problems for non-Dutch students since many documents needed for

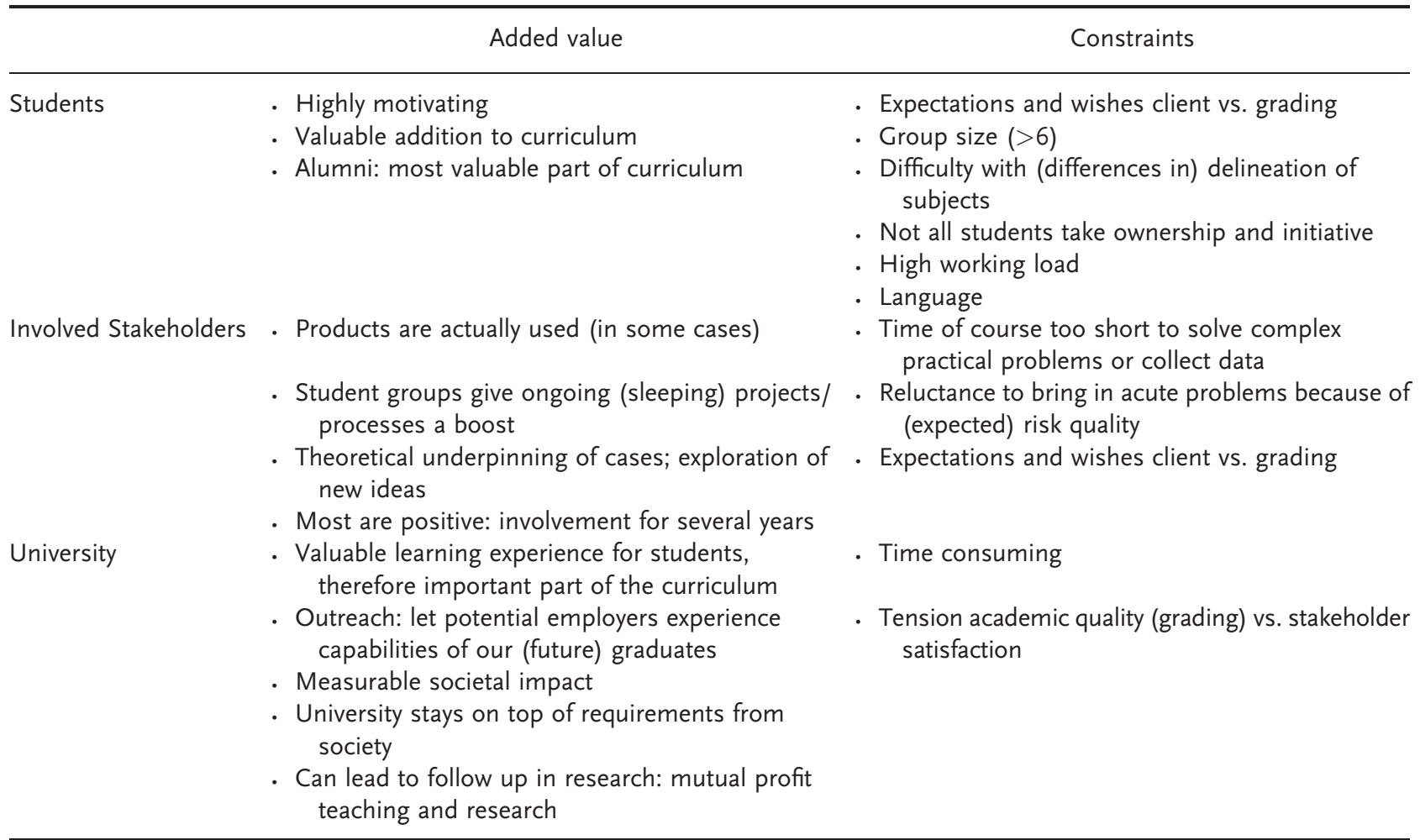

Table 3. Added value and constraints of the transdisciplinary courses, from the perspective of students, stakeholders and the university 
the project are in Dutch. These language problems mainly occurred in the MSc Transdisciplinary Case Study course, in which on average, $37 \%$ of the students have a non-Dutch nationality. Overall, students appreciate the real-world engagement offered by the courses. The added value of these transdisciplinary courses is appreciated even more by alumni, who, after working in real-life situations, consider them among the most valuable experiences of their academic training.

Stakeholders' Perspective

For the majority of the involved stakeholders, transdisciplinary cooperation has positive effects, which is reflected in their willingness to participate during consecutive years. In some cases, the added value for the stakeholders is clear if the solutions produced by the students are actually feasible for their organisation. In the Sustainable Business Case course during the last five years, we have worked with 75 companies asking for student input, of which 2I have returned at least once during this period, one of them twice and five of them in four of the five opportunities. Most of the participants are larger companies. Many come from small or medium-sized companies with limited resources for addressing environmental concerns.

In some cases, stakeholders report as an added value that the involvement of student groups gives ongoing and sometimes sleeping projects a boost. Moreover, they appreciate the theoretical underpinning of cases and the exploration of new ideas by the students.

A constraint of the current set up for the course projects is that the time of the course is too short (only four to ten weeks half-time) to really solve complex practical problems or to enable sufficient data collection. In some cases, stakeholders are reluctant to bring in acute problems because of (expected) end-quality risks related to involvement of inexperienced students (especially undergraduate students). Finally, involved stakeholders also report experiencing tension between their own expectations versus the grading requirements of the university.

\section{University Perspective}

The most important added value of the transdisciplinary course projects is that they provide valuable learning experiences for students and therefore are an important part of the curriculum. The contact with stakeholders also enables the university to stay on top of what society expects of graduates' competencies. Moreover, the projects provide societal stakeholders an opportunity to experience the capabilities and quality of our students. In a number of cases, students return to the stakeholder's organisation to perform an internship or become employed. In some cases, the cooperation between the involved professor and the societal stakeholder will lead to a cooperative commissioned research project as a follow up, thus resulting in a beneficial effect on teaching as well as research. On the other hand, the organisation and supervision of the transdisciplinary courses is a time consuming exercise (more time consuming than the preparation of a 'regular' course), which can be considered a major constraint from the perspective of the university. Finally, the tension between academic quality (grading) and stakeholder satisfaction is perceived as a constraint on this approach by the University as well.

\section{Discussion}

According to Brundiers and Wiek (2OII), if the goal of the learning experience is to engage students in real-world sustainability problems, then the cases addressed should have characteristics of actual sustainability problems. Moreover, projects should allow students to develop workable response and mitigation strategies for the problems at hand. Our analysis shows that, within the context of our courses, it is not realistically possible to meet all these requirements. Generally, our courses contain two types of case problems. In one type, complex sustainability problems are reduced into clearly delineated sub-problems of a more technical nature, thereby increasing the chances for students to come up with solutions that are of immediate added value to the stakeholder. This is especially the case in the Sustainable Business Case course. For the other type, especially in the Environmental Consultancy Project and the Transdisciplinary Case Study courses, sustainability problems with a higher level of complexity are addressed. In most of these cases, the level of complexity is too high and the time span is too short in order to develop workable solutions. Usually, subjects are brought in to test new ideas or to gain advice 
about subjects for which no budget is available. Annually, a number of students carry out follow-up projects in an internship, which more often leads to workable solutions.

According to the evaluative scheme by Brundiers and Wiek (20II), none of these courses fully meets the requirements for engagement with a real world sustainability problem. Whether this is considered problematic will depend strongly on the learning outcomes defined for the specific course in the context of the rest of the curriculum. In our view it is not problematic if a specific course does not fulfil all criteria as long as the requirements are sufficiently met at the level of the whole curriculum. Sustainable development curricula should contain an optimal mix of real-world learning opportunities, including transdisciplinary exercises in collaboration with societal stakeholders (potential employers).

We have noticed in several of our courses a tendency of newly involved stakeholders to be reluctant to bring in more acute sustainability problems because they fear a quality risk when students are involved. Practically in some cases, this results in assignments that are not well thought-through, and which may not have immediate applicability within the stakeholder's organisation. This may undermine student motivation, as has been indicated in the student evaluations of the Environmental Consultancy Project. Part of the solution may be longer term involvement of stakeholders in the course through which they may gain trust in the performance of students and their supervision by professors. Many of the stakeholder organisations involved in our three courses have expressed such commitment after participating in them. Stakeholder evaluations of the Sustainable Business Case course showed that on average in the last 3 years $61 \%$ of the companies were willing to receive another group of students the next year, while another $33 \%$ would possibly be willing to (depending on the conditions next year) and only $6 \%$ were not willing. In the Environmental Consultancy Project some of the stakeholders (municipality, Provincial government) have been involved in the course for several consecutive years.

The success of transdisciplinary courses largely depends on early and active involvement of professors with stakeholder organisations. However, the expectations and wishes of the client (societal stakeholder) with respect to the development of applicable solutions on the one hand, and the requirements of the university regarding academic quality and the need of grading on the other hand, creates a tension, felt by students, stakeholders and university supervisors alike. A main reason for this tension is the limited time span of 4 to Io weeks in which the project has to be completed, which is dictated by the university course schedules. This requires investment of time outside the course schedules, which may pose organisational difficulties. However, such investments create mutual commitment and improve the definition of the research problem and the learning outcomes for the students, as well as the generation of workable solutions for the stakeholder organisation. For the university, active involvement of professors in framing the sustainability problems together with stakeholders also necessitates an investment of time (also outside the course schedule), to get to know the stakeholders organisation and analyze the sustainability problem at hand, which may be felt as a constraint. On the other hand, an added value for the university may be that the mutual commitment and generation of quality results may lead to spin-off in the form of contract research and joint grant applications, which has been the case for several of our courses. The appointment of a neutral process facilitator is suggested by several authors (Tress et al., 2005; Van de Kerkhof and Wieczorek, 2005; Brundiers and Wiek, 20II) to help improve this cooperation process.

\section{Conclusion}

In conclusion, our analysis shows that students in the Bachelor's and Master's programmes of Environmental Sciences at Utrecht University are provided with ample opportunity to work on complex real-world problems, both inside and outside the classroom. The curriculum contains three transdisciplinary courses, in which students engage with real-world problems in cooperation with societal stakeholders. None of these three courses fully meets all requirements of 'good' sustainability research education as defined by Brundiers and Wiek (20II). However, in our view this is not considered necessary, as long as the curriculum as a whole provides adequate learning opportunities for students.

A sustainable development curriculum should therefore ideally contain a (workable) mix of real-world learning opportunities, including transdisciplinary exercises in collaboration with societal stakeholders. Following from the 
analysis of the three courses presented here, such courses can only successfully be implemented if lecturers can invest sufficient time in durable relations with relevant stakeholders and joint course preparation. Such long-term involvement aids stakeholders to better judge the possibilities and added value of student involvement in their practices. This could help to improve assignments and increase the applicability of student practice while motivating students. Finally, it will provide positive learning outcomes for students, university lecturers and stakeholders - the true objective of trans-disciplinarity.

\section{References}

Altomonte S, Rutherford P, Wilson R. 20I2. Mapping the way forward: Education for sustainability in the built environment. Corporate Social Responsibility and Environmental Management this issue.

Alvarez A, Rogers J. 2006. Going 'out there': Learning about sustainability in place. International Journal of Sustainability in Higher Education 7: I76-I88. DOI: го.1108/14676370610655940

Barth M, Godemann J, Rieckmann M, Stoltenberg U. 2007. Developing key competences for sustainable development in higher education. International Journal of Sustainability in Higher Education I8: 4I6-430. DOI: IO.IIO8/14676370710823582

Baumgartner R. 20I2. Sustainability manager: A business simulation for education and training on sustainability management. Corporate Social Responsibility and Environmental Management this issue.

Bootsma MC, Vermeulen WJV. 20II. Experiences of environmental professionals in practice. International Journal of Sustainability in Higher Education I2: 163-I76. DOI: I0.II08/1467637IIIII18219

Brundiers K, Wiek A. 20II. Educating students in real-world sustainability research: Vision and implementation. Innovative Higher Education 36: I07-I24. DOI: I0.1007/SI0755-0I0-9I6I-9

Brundiers K, Wiek A, Redman CR. 20Io. Real-world learning opportunities in sustainability: From classroom into the real world. International Journal of Sustainability in Higher Education II: 308-324. DOI: I0.II08/14676371011077540

Clark B, Button C. 20II. Sustainability transdisciplinary education model: Interface of arts, science, and community (STEM). International Journal of Sustainability in Higher Education I2: 4I-54. DOI: 10.1108/14676371111098294

Funtowitz SO, Ravetz JR. I993. Science for the post-normal age. Futures 25: 735-755. DOI: 10.1016/0016-3287(93)9022-L

Godemann, J. 2008. Knowledge integration: A key challenge for transdisciplinary cooperation. Environmental Education Research I4: 625-64I. DOI: $10.1080 / 13504620802469188$

Hessels L, Van Lente H. 2008. Re-thinking new knowledge production: A literature review and a research agenda. Research Policy 37: 740-460. DOI: I0.10I6/j.respol.2008.0I.008

Hofstede GJ, De Caluwé L, Peters V. 20Io. Why simulation games work-in search of the active substance: A synthesis. Simulation \& Gaming 4I: 824-843. DOI: Io.II77/I046878110375596

Holden M, Elverum D, Nesbit S, et al. 2008. Learning teaching in the sustainability classroom. Ecological Economics 64: 52I-533. DOI: I0.IOI6/j. ecolecon.2007.09.007

Jones P, Selby D, Sterling S. 20Io. More than the sum of their parts? Interdisciplinarity and sustainability. In Sustainability Education. Perspectives and Practice Across Higher Education, Jones P, Selby D, Sterling S (eds). Earthscan: London; pp I7-37.

Kearins K, Fryer M. 20II. Relating sustainability theory to practice at Auckland Airport: An engaged scholarship endeavour involving students. Corporate Social Responsibility and Environmental Management I8: I5I-I6I. DOI: I0.I002/csr.270

Mitchell PH. 2005. What's in a name? Multidisciplinarity, interdisciplinarity and transdisciplinarity. Journal of Professional Nursing 2I: $332-334$.

Muhar A, Vilsmaier U, Glanzer M, et al. 2006. Initiating transdisciplinarity in academic teaching. Experiences from a regional development project in Salzburg, Austria. International Journal of Sustainability in Higher Education 7: 293-306, DOI: 10.1108/14676370610677856

Pohl C. 2008. From science to policy through transdisciplinary research. Environmental Science Q Policy II: 46-53. DOI: IO.IOI6/j. envsci.2007.06.00I

Polk M, Knutsson P. 2008. Participation, value rationality and mutual learning in transdisciplinary knowledge production for sustainable development. Environmental Education Research I4: 643-653. DOI: I0.1080/1350462080246484I

Runhaar H, Driessen P, Vermeulen WJV. 2005. Policy competences of environmental sustainability professionals. Greener Management International 49: 25-4I.

Runhaar H, Dieperink C, Driessen P. 2006. Policy analysis for sustainable development: The toolbox for the environmental social scientist. International Journal of Sustainability in Higher Education 7: 34-56.

Schmidt JC. 2008. Towards a philosophy of interdisciplinarity. Poiesis and Praxis 5: 43-69. DOI: 10.1007/sio202-007-0037-8

Scholz RW, Mieg HA, Oswald JE. 2000. Transdisciplinarity in groundwater management - towards mutual learning of science and society. Water, Air, and Soil Pollution I23: 477-487.

Scholz RW, Lang DJ, Wiek A, et al. 2006. Transdisciplinary case studies as a means of sustainability learning: Historical framework and theory. International Journal of Sustainability in Higher Education 7: 226-251. DOI: 10.1108/14676370610677829

Sciglimpaglia D, Toole HR. 20I0. Use of student field-based consulting in business education: A comparison of American and Australian business schools. The Journal of Education for Business 85: 68-77. DOI: 10.1080/08832320903253619 
Stauffacher M, Walter AI, Lang DJ, et al. 2006. Learning to research environmental problems from a functional socio-cultural perspective: The transdisciplinary case study approach. International Journal of Sustainability in Higher Education 7: 252-275. DOI: IO.IIO8/ 14676370610677856

Steiner G, Laws D. 2006. How appropriate are two established concepts from higher education for solving complex real-world problems? International Journal of Sustainability in Higher Education 7: 322-340. DOI: 10.1108/14676370610677874

Steiner G, Posch A. 2006. Higher education for sustainability by means of transdisciplinary case studies: an innovative approach for solving complex, real-world problems. Journal of Cleaner Production I4: 877-890. DOI: I0.Ioi6/j.jclepro.2005.II.054

Tress B, Tress G, Fry G. 2005. Integrative studies on rural landscapes: Policy expectations and research practice. Landscape and Urban Planning 70: I77-I9ı. DOI: го.I0I6/j.landurbplan.2003.10.013

Van de Kerkhof M, Wieczorek A. 2005. Learning and stakeholder participation in transition processes towards sustainability: Methodological considerations. Technological Forecasting and Social Change 72: 733-747. DOI: I0.1016/j.techfore.2004.10.002

Van Egmond ND, de Vries HJM. 20II. Sustainability: The search for the integral worldview. Futures 43: 853-867. DOI: Io.IoI6/ j.futures.2011.05.027

Vincent S, Focht W. 2009. US higher education environmental program managers' perspectives on curriculum design and core competencies: Implications for sustainability as a guiding framework. International Journal of Sustainability in Higher Education Io: I64-I83. DOI: IO.IIO8/ I4676370910945963 